\title{
Triple Lock Security System using Arduino
}

\author{
${ }^{1}$ Krishnapriya Sreenadh \\ Electronics and Telecommunication \\ MAEER'S MIT polytechnic \\ Pune, India
}

${ }^{3}$ Mrs. Manjushri Joshi

Prof. Electronics and Telecommunication

MAEER'S MIT Polytechnic

Pune, India

\author{
${ }^{2}$ Harshal Kulkarni \\ Electronics and Telecommunication \\ MAEER'S MIT Polytechnic \\ Pune, India
}

\author{
${ }^{4}$ Mrs. Vijaya Pangave \\ Prof. Electronics and Telecommunication \\ MAEER'S MIT polytechnic \\ Pune, India
}

\begin{abstract}
Nowadays majority of the people are facing various problem about how to secure their important and personal belongings like important and valuable documents, ornaments and money kept in home, banks, etc due to the theft, people in our society is varied to keep their valuable things inside homes, offices and in organization. Hence, most of the people are using alarm to safeguard their lockers in home to provide proper security to their belongings. But still they can be operated with manual operations of lock system and key system without providing any of the information to the user when theft is happened by breaking them. Hence, we propose an advanced alert system for home, bank offices or any organization security system using fingerprint sensor, numeric keypad and RFID module for authenticating to open the servo door system. Our system provides the better security to all places where unauthorized people will not be allowed. And our system is very economical cost, so that it is affordable to everyone.
\end{abstract}

Keywords-Arduino Mega 2560, 4x4 Numeric Keypad, RFID Sensor with Card, Fingerprint Sensor and Servo motor.

\section{INTRODUCTION}

Our project aims to provide protection to everyone's valuable assets, to ensure the safety of valuable things and security of their valuable things which are stored in banks, homes. Which is important for security purpose of valuables? In present situation security has become an important issue for many people which are staying in rural or urban areas. To overcome this most of the people 1 try different types of locks and locking system. But these locks are not so reliable To solve this problem to develop a Triple lock Security system using Arduino with Fingerprint sensor, RFID sensor with Card and Numeric Keypad. Locker contains more security the present procedure as persisted than any other as low cost system to replace basic types of locks use for the operation of home, bank or any organization lockers used by the people.

\section{EASE OF USE}

Our project triple lock system is based on avoiding bank robbery, home robbery, because nowadays home security system means to protect your home and valuables and keep your family safe, always out of harm's way. When you leave for work, you expect to comeback to a smiling family, and to a home that is secure. But as they say, hope is not a strategy. The growing crime rates reflect the bitter reality.

Many people overlook, ignore and underestimate the need of taking appropriate home security measures. So for this we have to, make such security so we can able to leave our home without any tension.

\section{PREPARE YOUR PAPER BEFORE STYLING}

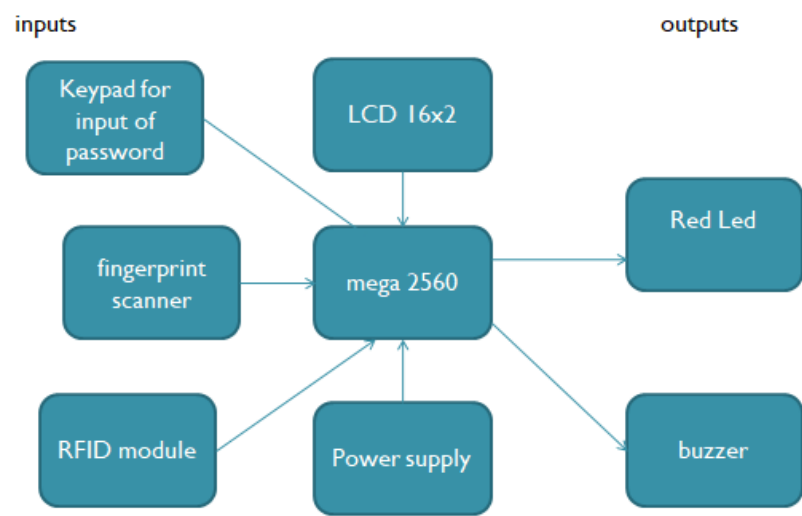

FIGURE 1. Block diagram of Triple Lock security system using Arduino

\section{WORKING OF SYSTEM}

In this project we are using Fingerprint sensor, RFID sensor and Numeric keypad for triple lock system. In this project we are using main controller which is not expensive as compared to any other controllers and ability to interface the entire three sensors work simultaneously. We are using Numeric keypad keypad in which we have to enter the password if the password is correct then only we can be able to access the further locks otherwise wrong password is shown on LCD display $16 * 2$. After that we have to show the card which has its unique Identification hen we cannot be able to proceed ahead towards the finger print sensor and at the last we have put thumb on sensor as we know that each person have its unique fingerprint identity and if its not going to match with it then the door lock will not be open. We use a servo motor 
as a lock in our project. If we put correct fingerprint on sensor then WELCOME is shown on LCD display $16 * 2$ another operation is that we also setup access indicator these is any operation performed by uses is wrong then the Red LED start glowing and the Buzzer will make an irritating noise. If the operation is correct then it will show Green LED and after 15 Seconds the servo motor automatically close as a safety purpose as a strong security.

\section{DESCRIPTION OF COMPONENTS}

\subsection{NUMERIC KEYPAD}

Numeric keypad is a number pad and it is a small sized 16 key section of a standard keypad. This 16-button numeric keypad provides a useful human interference of components for microcontroller. Which is convenient in adhesive backing provides an easy way for mounting the keypad in a various types of applications. It is a $4 \times 4$ keypad, which is flexible, and it also has 8 pins. This can also be used as an input for different application. It is also available in different size and shape. It is a low cost numeric keypad 4x4 membrane numeric keypad with a standard telephone type. Keypads can be used in all types of devices such as cell phones, fax machines, micro-waves, ovens, doors, locks, etc. Various types of electronic devices use that as a used input by knowing how to connect a keypad to a microcontroller such as Arduino. We can use Arduino for building different types of commercials products. It usually comes with no documentation so user is left to finger out a pin configuration. Keypad can be used as an input device to read the key pressed by user for processing. It is easy to interface with Arduino. Numeric keypad is also used for playing games. The matrix encoding schemes allows for less output pins so that have to be made for the keypad to work. Hence we require less number of connections to interface with Arduino Mega.

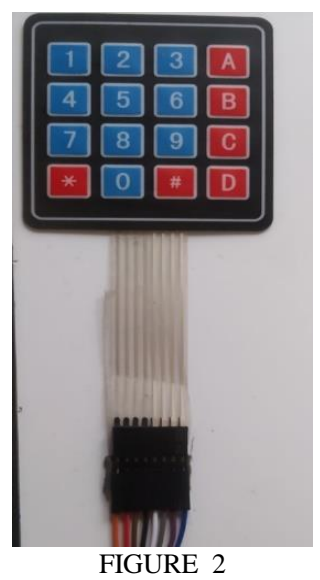

\subsection{FINGERPRINT SENSOR}

R307 fingerprint Module consists of optical fingerprint sensor, high-speed DSP processor, high performances, fingerprint algorithm, very high-capacity FLASH chips and also other hardware and software composition, which stable the performances, it is a very simple structure with fingerprint entry, image processing, fingerprint matching, search and template storage and other function: Fingerprint are one of the many unique biometric signatures which we can use to identify people vary accurately. In our project we use RC307 basically fingerprint sensor is one of the types of electronic security system which can be used at a biometric authentication to grant a user access information. Basically fingerprint scanner is used for recognize person and verify their identity.

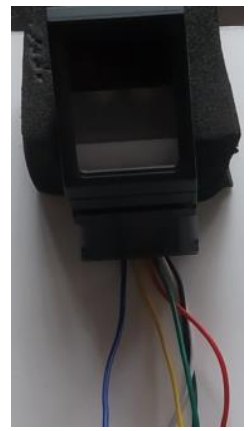

FIGURE 3

This is the analyzer of fingerprint which requires several features of print pattern RC307 sensor is small size, no external DSP chip algorithm, has been integrated, easy to install and less fault. RC307 fingerprint module is a two interface TTL UART and VB2.0 USB2.0 interface which can be connected to the computers. Fingerprint sensor is one kind of sensor which is used in a fingerprint detection device for interfacing of fingerprint sensor with Arduino Mega 2560. Ground pin of Fingerprint Sensor is connected to the Ground Vcc pin to the 5v and Rx pin to A4 and Tx to the A5 of the Arduino Mega 2560. For connecting Servo motor with Arduino Mega 2560 servo motor is first pin which is connected to ground, second pin to the Vcc and third pin to the digit pin 06 of the Arduino Mega 2560. We use Fingerprint Sensor along with RFID and Numeric keypad to add extra security which is convenient and user friendly and useful for creating the strong security.

\subsection{RFID WITH CARD}

RFID means RADIO FREQUENCY IDENTIFICATION. This is low cost MFRC522 based RFID Reader Module is easy to use and can be used in a wide range of application. The MFRC522 is a highly integrated reader/writer IC for contactless communication at $13.56 \mathrm{MHz}$ It is a chip based board. Its maximum data transfer rate is $10 \mathrm{Mbits} / 5$. IT dimensions is $60 \mathrm{~mm}$ and $39 \mathrm{~mm}$. An RFID tag is a smooth card which read by an RFID reader. IT works at $125 \mathrm{kHz}$ and has a unique ID 32-bit ID and each tag has a unique ID number which cannot be changed. In our project we are using RFID to add more advanced security and it is user friendly security along with Fingerprint Servo and Numeric Keypad.

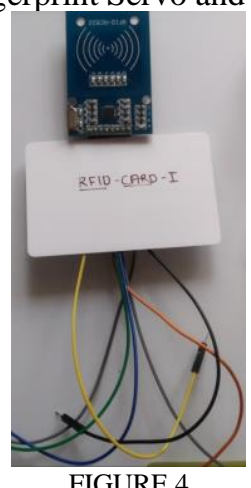


RFID works on radio frequency and also it is used for the auto identification for different types of objects. Basically RFID (Radio Frequency Identification) is used in electromagnetic fields for automatically identity the tags which are attached to cash, clothing, the possibility o reading personally linked information without any result raised in serious privacy concern, which is resulted in standard specifications development addressing privacy and security. RFID tags are consist of tiny transponder, a radio receiver and transmitter and when it is triggered by an electromagnetic integration pulse form a nearby RFID reader device then the tag transmitter the digital data usually an identifying numbers back to the reader. The Pin wiring of RFID reader with Arduino Mega 2560 is SDA Pin to Digital 11 MISO to Digital 121 RCS is connected Ground to Ground RST to Digital 9 and $3.3 \mathrm{~V}$ is should be given to it.

\subsection{ARDUINO MEGA 2560}

In our project we are using Arduino Mega 2560to interface with three sensors i.e. Fingerprint sensor, RFID sensor with card and Numeric Keypad. Arduino Mega 2560 is used for designing the projects which requires more $\mathrm{I} / \mathrm{O}$ lines, more memory and more RAM. Programming of Arduino Mega 2560 is based on Ardunio software i.e. IDE (Integrated Development Environment) which is common to all. This board works on both online and offline.

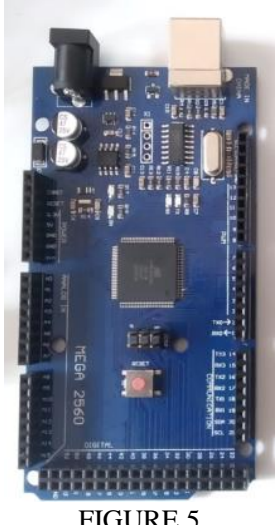

Ardunio Mega 2560 is the microcontroller which is based in At mega 2560 and it also have 5 digital I/O pins out of which 14 pins can be used as PWM output, 16 pins can be used as analog input, 4 UART (hardware serial ports), $16 \mathrm{MHz}$ crystal oscillator and the USB connections, power jack, an ICSP header and a reset button. It contains everything, which needed for supporting the microcontroller and simply connected to the computer with the USB cable or power with ac to dc adaptor or battery, which gets started. Therefore, we can say that the Mega is compatible with most shields designed for the Ardunio.

\section{ACKNOWLEDGMENT}

I am profoundly grateful to PROF. MANJUSHIR JOSHI \& PROF. VIJAYA PANGAVE for their expert guidance and continuous encouragement throughout to see that this project rights its target since its commencement to its completion.

I would like to express my deepest appreciation towards PROF. R.S. KALE Principal, PROF. ANURADHA BAKARE HOD of Electronics and Telecommunication Engineering Department whose invaluable guidance supported me in completing this project.

I am grateful to my friends for extending the help whenever it was need to my Mega Project. The work presented in this report would not have been completed without the contribution extended by all those whose names have not been mentioned here.

And all the staff members and non-teaching staff of Electronics \& Telecommunication Department who helped me directly or indirectly during this course of work.

Last but not the least, I owe a deep sense of gratitude to my Parents for the constant encouragement, motivation and patience to enable me to devote a considerable time for this accomplishment.

\section{REFERENCES}

[1] Basic Electronics by D.P Kothari and Nagrath.

[2] Classification and uses of the fingerprint sensor are by Henry, Edward R; Sir 1900.

[3] RFID Tag by Charles. A. Walton.

[4] Numeric Keypad by William and Hubert Hopkins.

[5] Arduino Mega 2560 by David, Justin Lahaut.

[6] Permanent magnet motor technology by Jacek F. Gierar.

[7] Smart Electronics Door lock Vardhan

[8] Physics and technology Brotherston. 